\title{
Fulvine and the pulmonary circulation
}

\author{
J. M. KAY, DONALD HEATH, PAUL SMITH, G. BRAS, \\ and JOAN SUMMERELL
}

Departments of Pathology, University of Liverpool and University of the West Indies

\begin{abstract}
The pyrrolizidine alkaloid, fulvine, is now accepted as a major cause of veno-occlusive disease of the liver in the West Indies, where it is ingested as a decoction of the plant Crotalaria fulva in bush tea. Fulvine is similar in chemical structure to monocrotaline, which is known to cause pulmonary hypertension in rats.

Thirty young female rats were given a single dose of fulvine either by intraperitoneal injection ( $50 \mathrm{mg} / \mathrm{kg}$ body weight) or by stomach tube $(80 \mathrm{mg} / \mathrm{kg}$ body weight). Eleven of these rats died of acute haemorrhagic centrilobular necrosis of the liver, and two of pneumonia, within 23 days of receiving fulvine. These 13 showed no evidence of hypertensive pulmonary vascular disease. The remaining 17 rats (which survived from 24 to 37 days) developed hypertensive pulmonary vascular disease with right ventricular hypertrophy together with medial thickening of the pulmonary trunk and muscular pulmonary arteries. The pulmonary arterioles showed hypertensive changes and some contained thrombi. In four animals an acute necrotizing arteritis also occurred.

We have shown that fulvine resembles monocrotaline in its ability to produce pulmonary hypertension in rats. We suggest that, in any patient presenting with unexplained pulmonary hypertension, a careful enquiry should be made to elicit the possibility of recent ingestion of drugs or plant extracts that may have caused a rise in the pulmonary arterial pressure.
\end{abstract}

Fulvine is a pyrrolizidine alkaloid contained in the foliage and seeds of Crotalaria fulva (Schoental, 1963). This leguminous plant is one of several which are used in the West Indies for the preparation of bush teas, which are consumed by the indigenous population for medicinal and other purposes. It is now generally accepted that fulvine and possibly other pyrrolizidine alkaloids contained in bush tea are the cause of veno-occlusive disease of the liver in the West Indies (Bras, Berry, and György, 1957 ; Bras and McLean, 1963). Until recently, veno-occlusive disease was the com- monest cause of hepatic cirrhosis in Jamaica (Bras, Brooks, and Watler, 1961).

Fulvine is closely related to monocrotaline (Fig. 1), a pyrrolizidine alkaloid contained in Crotalaria spectabilis. We have previously shown that when monocrotaline is given to rats by the oral or systemic routes they develop severe pulmonary arterial hypertension (Kay, Harris, and Heath, 1967). This is associated with right ventricular hypertrophy and thickening of the pulmonary trunk and muscular pulmonary arteries (Kay and Heath, 1966; Heath and Kay, 1967).

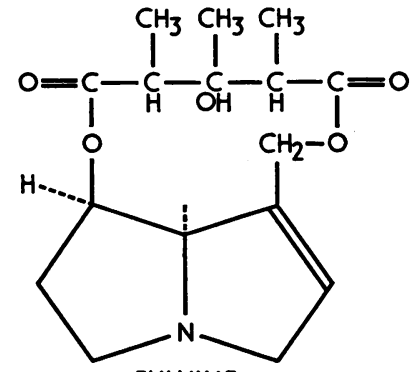

FULVINE

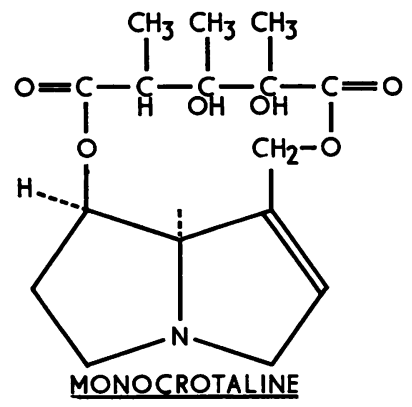

FIG. 1. Structural formulae of fulvine and monocrotaline. 
In about one-third of affected animals an acute necrotizing pulmonary arteritis also occurs. There have been several studies of the effect of fulvine on the liver (Barnes, Magee, and Schoental, 1964 ; McLean, Bras, and György, 1964 ; Gardiner, Royce, and Bokor, 1965) but no adequate investigation of its effect on the heart and lungs. In view of the close chemical similarity of fulvine and monocrotaline we decided to study the heart and pulmonary arteries of rats given fulvine to see if this alkaloid would also produce hypertensive pulmonary vascular disease.

\section{MATERIALS AND METHODS}

Forty young female Wistar albino rats (initial body weight 40 to $130 \mathrm{~g}$ ) were divided into two groups consisting respectively of 30 test animals (initial body weight 80 to $125 \mathrm{~g}$ ) and 10 controls (initial body weight 40 to $130 \mathrm{~g}$ ). The rats were weighed weekly until the conclusion of the experiment.

Fifteen of the test rats (nos 1 to 15, Table I) were given a single intraperitoneal injection of fulvine amounting to $50 \mathrm{mg}$ of the alkaloid per $\mathrm{kg}$ body weight. The remaining 15 test rats (nos 16 to 30 , Table II) were given a single dose of fulvine by stomach tube, equivalent to $80 \mathrm{mg}$ of the alkaloid per $\mathrm{kg}$ body weight. The pure alkaloid was dissolved in $\frac{\mathrm{N}}{10}$ hydrochloric acid and then the $\mathrm{pH}$ was adjusted to $7 \cdot 4$ by adding $\mathrm{N}$ sodium hydroxide. This solution was diluted with distilled water to make up a solution containing $10 \mathrm{mg}$ of fulvine per $\mathrm{ml}$ for administration by the intraperitoneal or intragastric routes as described above. Ten rats (nos 31 to 40, Table III) were kept as controls. All the animals had free access to a diet of rat cubes and water.

\section{T A B LE I}

SURVIVAL TIME, CARDIAC AND FINAL BODY WEIGHTS, PT/A RATIOS, AND MEDIAL THICKNESS OF MUSCULAR PULMONARY ARTERIES IN 15 RATS GIVEN AN INTRAPERITONEAL INJECTION OF FULVINE

\begin{tabular}{|c|c|c|c|c|c|c|c|c|}
\hline \multirow{2}{*}{$\begin{array}{l}\text { Rat } \\
\text { No. }\end{array}$} & \multirow{2}{*}{$\begin{array}{c}\text { Survival } \\
\text { Time } \\
\text { (days) }\end{array}$} & \multirow{2}{*}{$\begin{array}{r}\text { Final } \\
\text { Body } \\
\text { Wt. (g) }\end{array}$} & \multicolumn{3}{|c|}{ Cardiac Weights $(\mathrm{g}) \times 10^{4}$} & \multirow{2}{*}{$\frac{\mathbf{L V}+\mathbf{S}}{\mathbf{R V}}$} & \multirow{2}{*}{$\frac{\mathbf{P T}}{\mathbf{A}}$} & \multirow{2}{*}{ MT $\%$} \\
\hline & & & $\mathbf{L V}+\mathbf{S}$ & $\mathbf{R V}$ & Total & & & \\
\hline $\begin{array}{r}1 \\
2 \\
3 \\
4 \\
5 \\
6 \\
7 \\
8 \\
9 \\
10 \\
11 \\
12 \\
13 \\
14 \\
15\end{array}$ & $\begin{array}{r}32 \\
29 \\
3 \\
29 \\
29 \\
29 \\
37 \\
29 \\
35 \\
29 \\
22 \\
37 \\
24 \\
32 \\
37\end{array}$ & $\begin{array}{l}105 \\
115 \\
100 \\
110 \\
110 \\
130 \\
125 \\
110 \\
130 \\
130 \\
90 \\
140 \\
110 \\
155 \\
152\end{array}$ & $\begin{array}{l}3310 \\
3762 \\
1896 \\
3898 \\
3020 \\
4760 \\
3956 \\
3535 \\
3869 \\
4093 \\
2928 \\
4230 \\
4943 \\
3383 \\
4210\end{array}$ & $\begin{array}{r}2265 \\
3246 \\
662 \\
4399 \\
2503 \\
3697 \\
3134 \\
2684 \\
4565 \\
4442 \\
982 \\
5106 \\
3090 \\
3637 \\
2895\end{array}$ & $\begin{array}{r}6154 \\
7368 \\
2748 \\
8864 \\
5907 \\
9340 \\
8012 \\
6647 \\
9202 \\
9427 \\
4261 \\
10079 \\
9189 \\
8429 \\
7829\end{array}$ & $\begin{array}{l}1.46 \\
1.16 \\
2.86 \\
0.90 \\
1.20 \\
1.29 \\
1.26 \\
1.32 \\
0.85 \\
0.92 \\
2.98 \\
0.82 \\
1.60 \\
0.93 \\
1.45\end{array}$ & $\begin{array}{l}1.07 \\
1.34 \\
0.18 \\
1.34 \\
1.25 \\
1 \cdot 15 \\
1.30 \\
1 \cdot 10 \\
1.41 \\
1.47 \\
0.76 \\
1.06 \\
1.09 \\
1 \cdot 16 \\
1 \cdot 11\end{array}$ & $\begin{array}{r}13.6 \\
15.7 \\
4.4 \\
14.1 \\
13.3 \\
15.4 \\
14.8 \\
9.6 \\
12.6 \\
15.8 \\
7.4 \\
13.9 \\
14.9 \\
15.9 \\
16.6\end{array}$ \\
\hline
\end{tabular}

Key: (Also applies to TABLES II and III)

$\mathbf{L V}+\mathbf{S}=$ left ventricle and interventricular septum

$\underline{L V}+\mathbf{S}=$ inverse ratio of right to left ventricular weight

RV

$\mathbf{R V}=$ right ventricle

$\underline{\mathrm{PT}}=$ ratio of medial thickness of pulmonary trunk to

MT = average percentage medial thickness of muscular pulmonary arteries

T A B L E I I

SURVIVAL TIME, CARDIAC AND FINAL BODY WEIGHTS, PT/A RATIOS, AND MEDIAL THICKNESS OF MUSCULAR PULMONARY ARTERIES IN 15 RATS GIVEN INTRAGASTRIC FULVINE

\begin{tabular}{|c|c|c|c|c|c|c|c|c|}
\hline \multirow{2}{*}{ Rat No. } & \multirow{2}{*}{$\begin{array}{c}\text { Survival } \\
\text { (dime } \\
\text { (days) }\end{array}$} & \multirow{2}{*}{$\begin{array}{l}\text { Final } \\
\text { Body } \\
\text { Wt. (g) }\end{array}$} & \multicolumn{3}{|c|}{ Cardiac Weights $(\mathrm{g}) \times 10^{4}$} & \multirow{2}{*}{$\frac{\mathbf{L V}+\mathbf{S}}{\mathrm{RV}}$} & \multirow{2}{*}{$\frac{\mathbf{P T}}{\mathrm{A}}$} & \multirow{2}{*}{ MT \% } \\
\hline & & & $\mathbf{L V}+\mathbf{S}$ & $\mathbf{R V}$ & Total & & & \\
\hline $\begin{array}{l}16 \\
17 \\
18 \\
19 \\
20 \\
21 \\
22 \\
23 \\
24 \\
25 \\
26 \\
27 \\
28 \\
29 \\
30\end{array}$ & $\begin{array}{r}10 \\
7 \\
10 \\
15 \\
23 \\
35 \\
23 \\
35 \\
31 \\
35 \\
12 \\
15 \\
11 \\
10 \\
10\end{array}$ & $\begin{array}{r}83 \\
120 \\
102 \\
165 \\
295 \\
122 \\
80 \\
120 \\
120 \\
140 \\
76 \\
150 \\
105 \\
102 \\
65\end{array}$ & $\begin{array}{l}2238 \\
2736 \\
1465 \\
2443 \\
2806 \\
3610 \\
2491 \\
4073 \\
3923 \\
4007 \\
1812 \\
2216 \\
1785 \\
2054 \\
2015\end{array}$ & $\begin{array}{r}496 \\
785 \\
674 \\
596 \\
1045 \\
3016 \\
890 \\
3114 \\
2094 \\
2532 \\
781 \\
508 \\
418 \\
470 \\
548\end{array}$ & $\begin{array}{l}3189 \\
3722 \\
2292 \\
3290 \\
4200 \\
7320 \\
3863 \\
7191 \\
6485 \\
7213 \\
2993 \\
2916 \\
2323 \\
2753 \\
2919\end{array}$ & $\begin{array}{l}4 \cdot 51 \\
3 \cdot 48 \\
2 \cdot 17 \\
4 \cdot 10 \\
2 \cdot 68 \\
1 \cdot 20 \\
2 \cdot 80 \\
1 \cdot 31 \\
1 \cdot 87 \\
1 \cdot 58 \\
2 \cdot 32 \\
4 \cdot 36 \\
4 \cdot 27 \\
4 \cdot 40 \\
3 \cdot 67\end{array}$ & $\begin{array}{l}0.44 \\
0.55 \\
0.46 \\
0.38 \\
0.41 \\
0.98 \\
0.78 \\
1.14 \\
1.01 \\
1.16 \\
0.62 \\
0.30 \\
0.37 \\
0.46 \\
0.26\end{array}$ & $\begin{array}{r}5.6 \\
5.1 \\
3.9 \\
6.5 \\
3.0 \\
13.5 \\
7.6 \\
11.8 \\
9.7 \\
10.1 \\
4.5 \\
4.1 \\
3.5 \\
3.8 \\
5.3\end{array}$ \\
\hline
\end{tabular}


T A B L E I I I

SURVIVAL TIME, CARDIAC AND TOTAL BODY WEIGHTS, PT/A RATIOS, AND MEDIAL THICKNESS OF MUSCULAR PULMONARY ARTERIES IN 10 CONTROL RATS

\begin{tabular}{|c|c|c|c|c|c|c|c|c|}
\hline \multirow{2}{*}{$\begin{array}{l}\text { Rat } \\
\text { No. }\end{array}$} & \multirow{2}{*}{$\begin{array}{c}\text { Survival } \\
\text { Time } \\
\text { (days) }\end{array}$} & \multirow{2}{*}{$\begin{array}{c}\text { Final } \\
\text { Body } \\
\text { Wt. (g) }\end{array}$} & \multicolumn{3}{|c|}{ Cardiac Weights $(\mathrm{g}) \times 10^{4}$} & \multirow{2}{*}{$\frac{\mathbf{L V}+\mathbf{S}}{\mathbf{R V}}$} & \multirow{2}{*}{$\frac{\mathbf{P T}}{\mathbf{A}}$} & \multirow{2}{*}{$\mathbf{M T} \%$} \\
\hline & & & $\mathbf{L V}+\mathbf{S}$ & $\mathbf{R V}$ & Total & & & \\
\hline $\begin{array}{l}\mathbf{3 1} \\
\mathbf{3 2} \\
\mathbf{3 3} \\
\mathbf{3 4} \\
\mathbf{3 5} \\
\mathbf{3 6} \\
\mathbf{3 7} \\
\mathbf{3 8} \\
\mathbf{3 9} \\
\mathbf{4 0}\end{array}$ & $\begin{array}{l}37 \\
37 \\
23 \\
31 \\
31 \\
31 \\
32 \\
35 \\
35 \\
37\end{array}$ & $\begin{array}{l}165 \\
220 \\
140 \\
212 \\
235 \\
170 \\
165 \\
180 \\
180 \\
160\end{array}$ & $\begin{array}{l}3503 \\
4684 \\
3256 \\
4500 \\
4018 \\
3933 \\
3823 \\
3648 \\
3916 \\
3617\end{array}$ & $\begin{array}{r}1007 \\
1072 \\
878 \\
898 \\
1447 \\
447 \\
958 \\
804 \\
1078 \\
784\end{array}$ & $\begin{array}{l}5124 \\
6193 \\
4443 \\
6260 \\
5950 \\
4961 \\
5056 \\
5061 \\
5393 \\
4874\end{array}$ & $\begin{array}{l}3.48 \\
4 \cdot 37 \\
3 \cdot 71 \\
5.01 \\
2 \cdot 77 \\
8.80 \\
4.00 \\
4.53 \\
3.63 \\
4.61\end{array}$ & $\begin{array}{l}0.39 \\
0.52 \\
0.39 \\
0.30 \\
0.33 \\
0.44 \\
0.48 \\
0.56 \\
0.48 \\
0.45\end{array}$ & $\begin{array}{l}3.6 \\
4.8 \\
4.5 \\
3.2 \\
2.8 \\
2.8 \\
3.8 \\
3.9 \\
6.2 \\
3.8\end{array}$ \\
\hline
\end{tabular}

With five exceptions, the test rats were allowed to die spontaneously, the length of survival of the individual animals being shown in Tables $I$ and II. Rats 18 and 20 were killed with ether when moribund on the 20th and 23rd days of the experiment respectively. The first test rat (no 3) died spontaneously on the 3rd day of the experiment and the last three test rats (nos 7, 12, and 15) were killed on day 37 to terminate the experiment. Control rats (Table III) were killed with ether on days $23,31,32,35$, and 37 .

Necropsy was carried out as soon as possible after the death of the test and control animals. The thoracic viscera were removed and the lungs were distended through the trachea with $10 \%$ formol saline until the pleural surfaces were smooth. The thoracic contents were then immersed in the same solution until fixation was complete. The liver was cut into thin slices and fixed in $10 \%$ formol saline.

After fixation the pulmonary trunk and ascending aorta were dissected free from the heart and embedded in paraffin wax. Transverse sections of both arteries were cut at $5 \mu$ thickness and stained by Lawson's modification of the Weigert-Sheridan method for elastic tissue with counterstaining by van Gieson's reagents for collagen and muscle. The sections were cut at the same distance from the semilunar valves in each instance so that the thicknesses of the medial coats of the two arteries could be compared. The media in each instance was composed of muscle and elastic tissue as described below and was clearly delineated from the intima and the thick fibrous adventitia, the thicknesses of which were excluded from the measurements. The sections were examined with a microscope fitted with a calibrated eyepiece micrometer. Ten measurements of the medial thickness were made on each artery and from these one mean medial thickness was calculated. The mean medial thickness of the pulmonary trunk (PT) was expressed as a ratio of the mean medial thickness of the aorta (A). This 'PT' ratio is used to express our results in the tables and graphs.

When fixation was complete the heart was opened. Blood and excess fixative were removed by blotting with fine gauze, and the cardiac chambers were divided using the method described by Fulton, Hutchinson, and Morgan Jones (1952). The free wall of the right ventricle was dissected from the remainder of the heart and weighed. The left ventricle with the attached interventricular septum were weighed together, and the two atria were weighed together. The presence of right ventricular hypertrophy was assessed by expressing the weight of the free wall of the right ventricle as an inverse ratio of the weight of the left ventricle and interventricular septum. The use of this ratio excludes the influence of body weight in making comparisons of right ventricular mass. The greater the degree of right ventricular hypertrophy, the smaller the ratio of left to right ventricular weight.

Blocks of tissue were taken from the left lung and from each of the superior, middle, inferior, and median lobes of the right lung. Sections of paraffinembedded tissue were cut at $5 \mu$ thickness and stained with haemotoxylin and eosin, by the elastic-van Gieson technique described above, by Perls' method for demonstrating ferric iron, and by the MartiusScarlet-Blue method for fibrin (Lendrum, Fraser, Slidders, and Henderson, 1962). Sections stained by the elastic-van Gieson method were examined with a microscope fitted with a calibrated eyepiece micrometer for measurement of the medial thickness and external diameter of muscular pulmonary arteries. Muscular pulmonary arteries consist of a muscular media bounded by internal and external elastic laminae. A total of between 10 and 40 such arteries (mean 22) was examined in each of the control and test rats. Only arteries which were virtually circular in transverse section were measured. The external diameter was taken as the mean of two measurements, at right angles to each other, of the distance between diametrically opposite points on the external elastic lamina. The medial thickness was estimated as the mean of four measurements taken at approximately equally spaced points around the vessel wall. The medial thickness was then expressed as a percentage of the external diameter. A value for the average percentage medial thickness (MT) in each animal was obtained by totalling all the percentage 

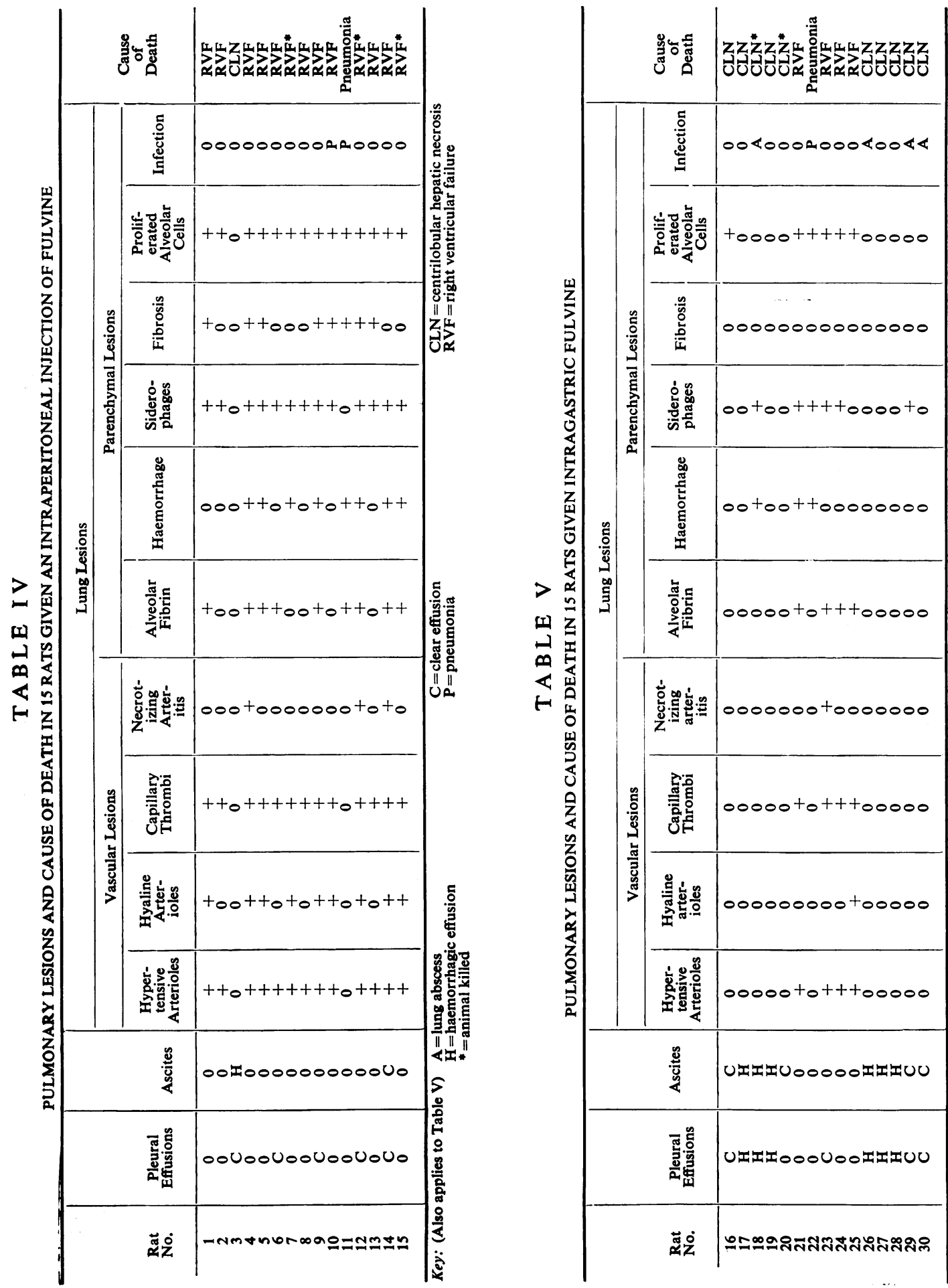
medial thicknesses and dividing the sum by the number of vessels examined.

Sections of paraffin-embedded liver tissue were stained with haematoxylin and eosin and by Gomori's (1950) trichrome connective tissue stain.

\section{RESULTS}

MACROSCOPIC FINDINGS AT NECROPSY Ascites was present in 12 of the 30 test rats (Tables IV and V). The volume ranged from less than $10 \mathrm{ml}$ to as much as $125 \mathrm{ml}$. The fluid was clear and watery in five cases and bloodstained in seven. Pleural effusions were seen in 15 test rats. In 11 cases there was an associated ascites, while in four cases the pleural effusions were solitary (Tables IV and V). The pleural fluid was clear and watery in nine cases but haemorrhagic in the remainder. Three tests rats (nos 3, 20, and 27) showed subcutaneous oedema of the anterior abdominal and thoracic walls.

The untreated control rats showed no abnormality at necropsy.

CAUSE OF DEATH Assessment of the right ventricular weight and subsequent histological examination of the liver, lungs, and pulmonary vasculature revealed that 11 of the 30 test rats died of an extensive haemorrhagic centrilobular necrosis of the liver, and two of pneumonia within 23 days of receiving fulvine. The remaining 17 rats survived longer than 23 days, developed hypertensive pulmonary vascular disease, and eventually died of right ventricular failure. The rats which died of liver disease or pneumonia showed no signs of hypertensive pulmonary vascular disease, while animals dying of right ventricular failure showed relatively insignificant hepatic lesions. The cause of death in each test rat is given in Tables IV and $\mathrm{V}$.

In the following paragraphs we show the development of right ventricular hypertrophy and describe the pulmonary vascular and parenchymal lesions. We shall not deal with the hepatic lesions in this paper because they have previously been described in detail by other workers (Barnes et al., 1964 ; McLean et al., 1964).

Right ventricular hypertrophy The total heart weight, the weights of the individual ventricles, and the right ventricular weight expressed as an inverse ratio of the weight of the left ventricle and interventricular septum $(L V+S / R V)$ are shown in Tables I, II, and III.

Figure 2 shows the relation between survival time and the $L V+S / R V$ ratio in the test and control rats. According to Fulton et al. (1952), isolated right ventricular hypertrophy may be considered to be present in man when the LV $+\mathrm{S} / \mathrm{RV}$ ratio is less than $2 \cdot 0$. This criterion for the assessment of right ventricular hypertrophy also applies in the rat (Kay and Heath, 1969). The graph shows that there was no evidence of right ventricular hypertrophy in the 13 test rats which died within 23 days of receiving a single dose of fulvine, since in these animals the LV+ S/RV ratio was greater than $2 \cdot 0$. The test rats which survived longer than 23 days all showed quantitative evidence of right ventricular hypertrophy because the $L V+S / R V$ ratio was less than $2 \cdot 0$.

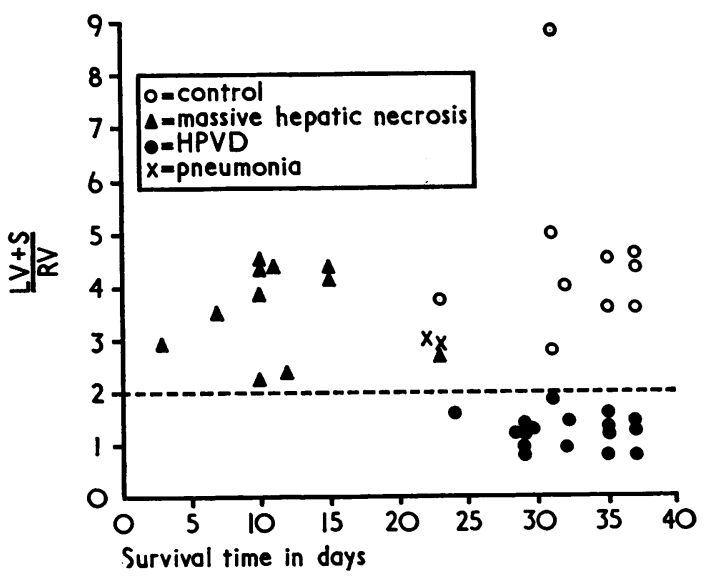

FIG. 2. Relation between right ventricular weight and survival time in control and test rats. The right ventricular weight $(R V)$ is expressed as an inverse ratio of the weight of the left ventricle and interventricular septum $(L V+S)$. The lower limit of normal of the $L V+S / R V$ ratio is indicated by the interrupted horizontal line.

\section{HYPERTENSIVE PULMONARY VASCULAR DISEASE}

The pulmonary blood vessels of the 13 rats without right ventricular hypertrophy which died of liver disease or pneumonia within 23 days of receiving fulvine were normal. The 17 rats which survived longer than 23 days and developed right ventricular hypertrophy all showed evidence of hypertensive pulmonary vascular disease. Lesions were present in the pulmonary trunk, muscular pulmonary arteries, pulmonary arterioles, and alveolar capillaries. The distribution of the various lesions in the test rats is summarized in Tables IV and $\mathrm{V}$. 
PULMONARY TRUNK The tunica media of the pulmonary trunk in normal rats consists of several long, unbranched, concentric elastic laminae separated from one another by circularly orientated smooth muscle fibres (Fig. 3). This musculoelastic media is sharply delineated from the intimal endothelial cell layer on its inner aspect, and from the thick fibrous adventitia on its outer aspect.

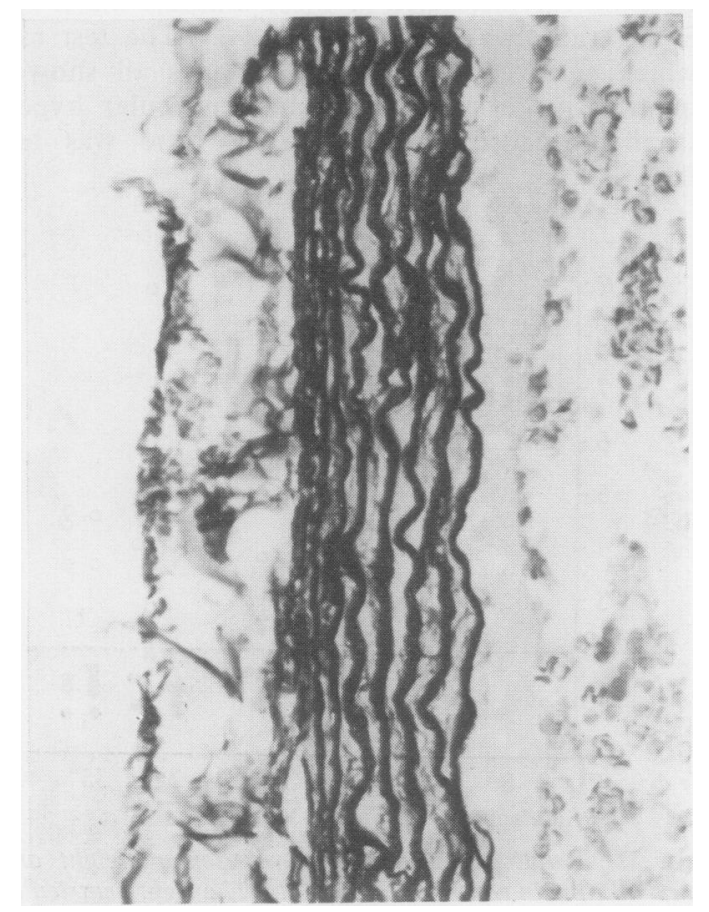

FIG. 3. Control rat. Transverse section of pulmonary trunk. The media consists of long, unbranched, concentric elastic laminae separated by smooth muscle fibres. Elasticvan Gieson $\times 375$.

The pulmonary trunk in the 17 test rats with right ventricular hypertrophy showed medial thickening due to the development of new muscle in between the elastic laminae causing them to be widely separated (Fig. 4). Some of these elastic laminae were uneven, branched, and even fragmented. Fine elastic fibrils were seen between the main laminae. The external elastic lamina was indistinct and there was a proliferation of smooth muscle in the adventitia.

Figure 5 shows the relation between the medial thickness of the pulmonary trunk and survival time in control and test rats. The medial thickness of the pulmonary trunk has been expressed

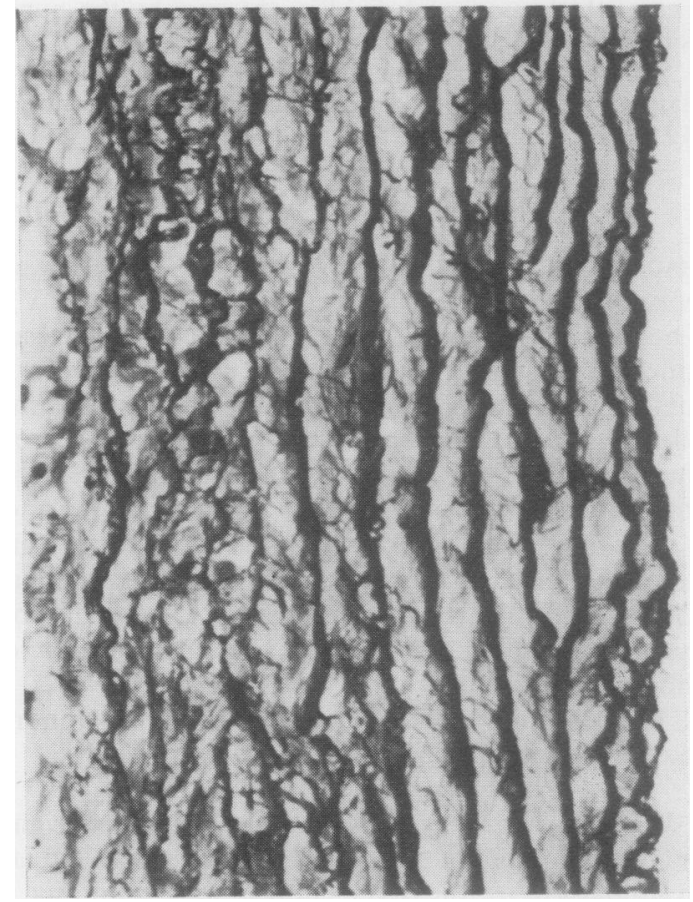

FIG. 4. Thickened pulmonary trunk from test rat which $\overrightarrow{\overrightarrow{0}}$ died of right ventricular failure. The elastic laminae are 3 uneven and fragmented and are widely separated by hypertrophied smooth muscle fibres. Elastic-van Gieson $\times 375$.

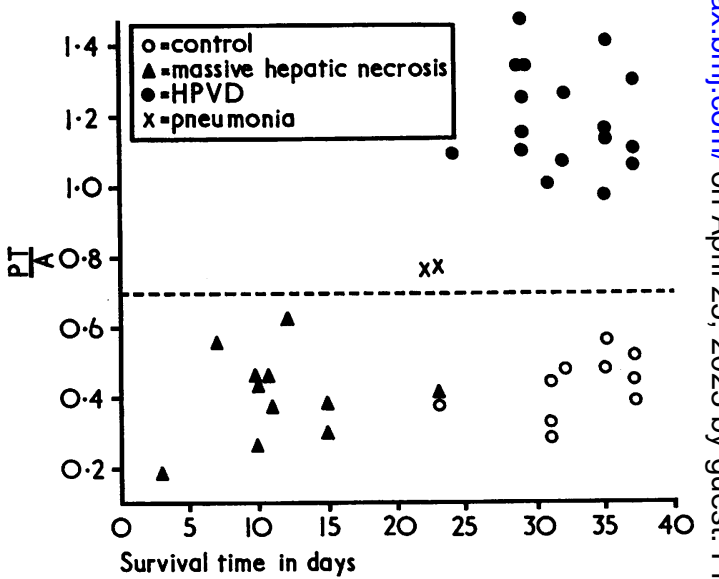

FIG. 5. Relation between medial thickness of pulmonary trunk and survival time in control and test rats. The $\stackrel{\mathbb{Q}}{\oplus}$ medial thickness of the pulmonary trunk $(P T)$ is expressed $\mathbb{\Phi}$ as a ratio of the medial thickness of the aorta $(A)$. The upper limit of normal of the PT/A ratio is indicated by the interrupted horizontal line. 
as a ratio of the medial thickness of the aorta (PT/A ratio). In man the $\mathrm{PT} / \mathrm{A}$ ratio does not normally exceed 0.7 after the age of 2 years (Heath, Wood, Du Shane, and Edwards, 1959), and this criterion for assessing the presence of medial hypertrophy of the pulmonary trunk also applies to the rat (Kay and Heath, 1969). The graph reveals that the animals with right ventricular hypertrophy also show measurable medial thickening of the pulmonary trunk. The PT/A ratio in each of the control and test rats is given in Tables I, II, and III.

MUSCULAR PULMONARY ARTERIES We define a muscular pulmonary artery in a rat to be an arterial vessel with an external diameter lying between $20 \mu$ and $400 \mu$. It has a media of circularly orientated smooth muscle fibres which does not normally exceed $7 \%$ of this external diameter (Fig. 6); the media is bounded by internal and external elastic laminae (Kay and Heath, 1966).

The 17 test rats which developed right ventricular hypertrophy also showed medial hypertrophy of their muscular pulmonary arteries, the

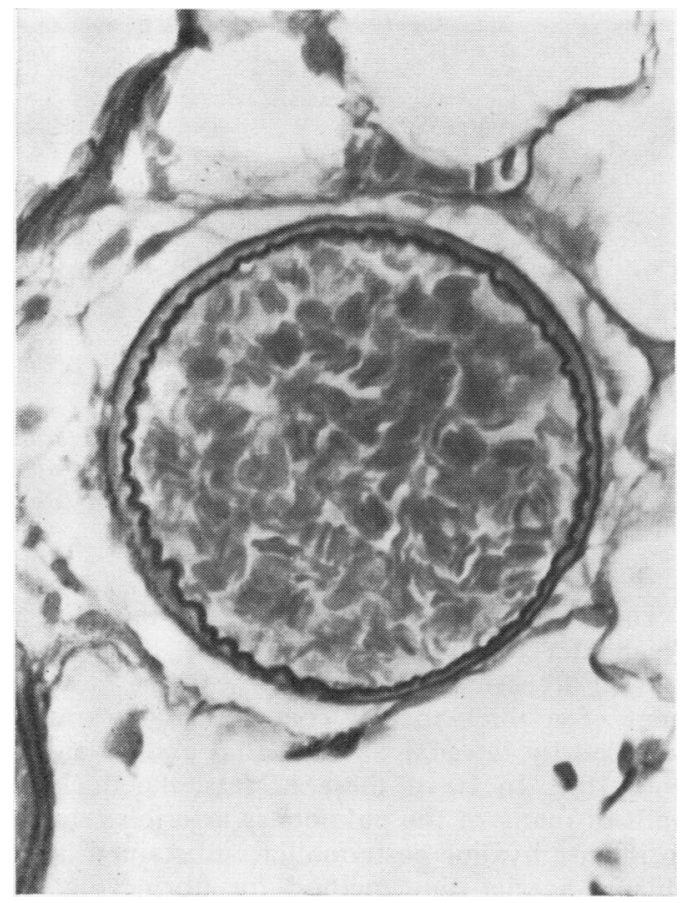

FIG. 6. Control rat. Muscular pulmonary artery. The thin muscular media is bounded by internal and external elastic laminae. Elastic-van Gieson $\times 600$.



FIG. 7. Relation between average medial thickness of muscular pulmonary arteries and survival time in control and test rats. The upper limit of normal of the average medial thickness is shown by the interrupted horizontal line.

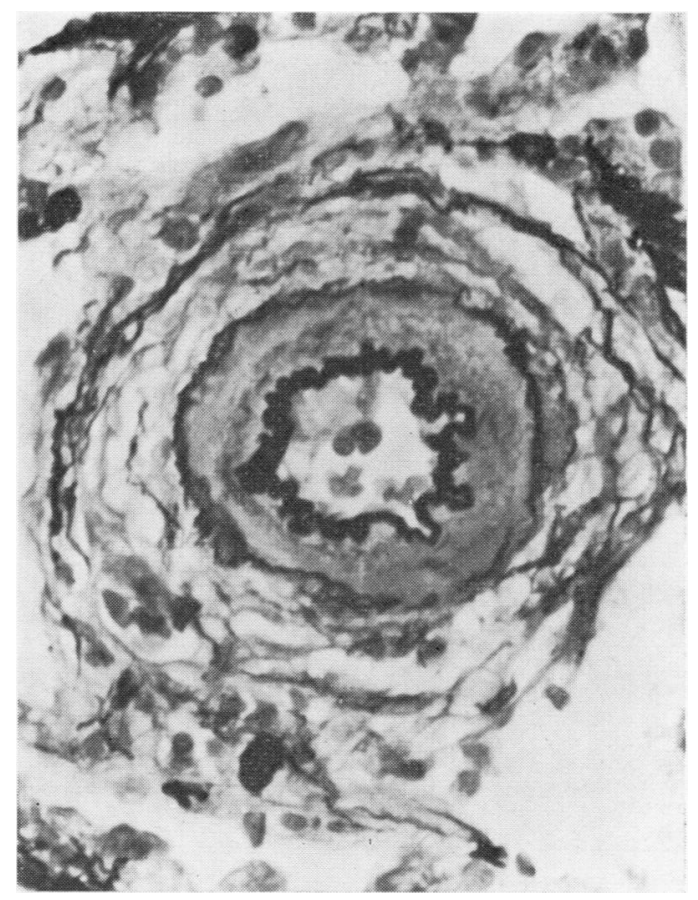

FIG. 8. Muscular pulmonary artery from test rat which died of right ventricular failure. The media is thick. Compare with Fig. 6. Elastic-van Gieson $\times 600$. 
average medial thickness ranging from $9.6 \%$ to $16.6 \%$ (Fig. 7). The thickened media consisted of circularly orientated smooth muscle fibres (Fig. 8); no longitudinal muscle was found, neither was there any form of intimal proliferation. The average percentage medial thickness for each of the test and control rats is given in Tables I, II, and III.

In 4 of the 17 test rats with hypertensive pulmonary vascular disease, several of the larger muscular pulmonary arteries ranging in external diameter from $200 \mu$ to $400 \mu$ showed an acute necrotizing arteritis (Fig. 9). The inflammatory process commonly involved the entire circumference of the artery, but occasionally only a small segment was involved. The intimal surface of these vessels was covered by a layer of adherent thrombus which was sometimes so thick as to cause partial blockage of the lumen. The muscular media was intensely eosinophilic and was infiltrated by scanty neutrophil polymorphs. The adventitia was thickened by a zone of vascular fibroblastic tissue infiltrated by neutrophil polymorphs, lymphocytes, and plasma cells. The

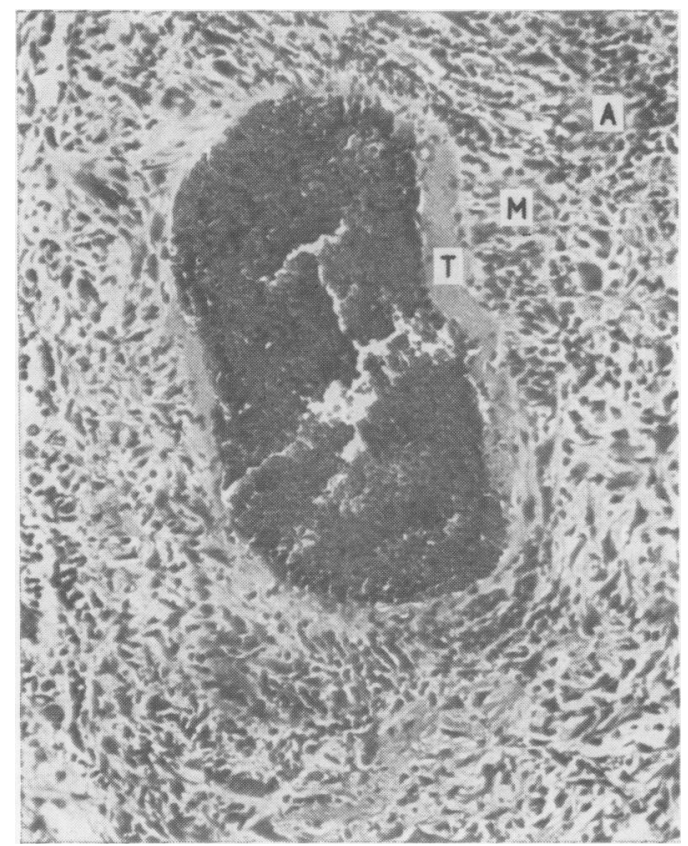

FIG. 9. Acute pulmonary arteritis in a test rat which died of right ventricular failure. The media $(M)$ is necrotic and infiltrated by neutrophil polymorphs, which extend out into the adventitia $(A)$. The intima is covered by thrombus $(T)$. Haematoxylin and eosin $\times 150$. internal elastic lamina remained intact, but there was patchy destruction of the external elastic lamina.

PULMONARY ARTERIOLES The normal pulmonary arteriole in a rat is an arterial vessel less than $20 \mu$ in diameter. Its wall is normally devoid of muscle and consists simply of a single elastic lamina lined by endothelial cells.



FIG. 10. Test rat. Hypertensive pulmonary arteriole. $A$ thick medial coat of smooth muscle is bounded by internal and external elastic laminae. Elastic-van Gieson $\times 1,500$.

The pulmonary arterioles of all the 17 rats which developed right ventricular hypertrophy showed hypertensive changes with the development of a thick medial coat of circular muscle bounded by internal and external elastic laminae (Fig. 10). In 10 of these 17 rats, the thickened walls of many of the pulmonary arterioles showed an intense hyaline eosinophilia and stained by the Martius-Scarlet-Blue method for fibrin (Fig. 11).

ALVEOLAR CAPILLARIES In all the 17 rats with right ventricular hypertrophy, many of the smaller pulmonary arterioles and alveolar capillaries were 


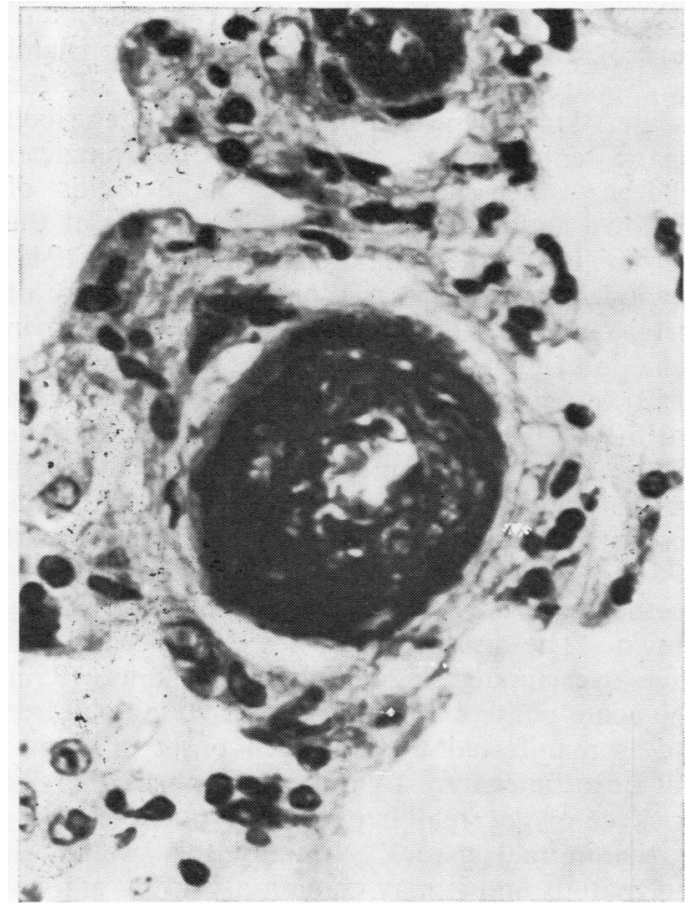

FIG. 11. Test rat. Hypertensive pulmonary arteriole. The thickened wall is stained by the Martius-Scarlet-Blue method for fibrin $\times 600$.

occluded by thrombi (Fig. 12). These thrombotic lesions were frequently accompanied by focal haemorrhages into the surrounding alveolar spaces.

\section{LESIONS IN THE LUNG PARENCHYMA}

The parenchymal lesions which occurred in the lungs of the 30 test rats are listed in Tables IV and $\mathrm{V}$. Infective lesions consisting of either bronchopneumonia or multiple pyaemic abscesses were noted in seven test rats. A severe confluent bronchopneumonia was considered to be the cause of death in two animals (nos 11 and 22) which showed no signs of major hepatic disease or right ventricular failure. No significant infective lesions were seen in the lungs of any of the 10 control rats.

The lungs of all the 17 test rats with right ventricular hypertrophy and hypertensive pulmonary vascular disease showed parenchymal lesions which appeared to be the direct or indirect result of exudation of blood or plasma from the small pulmonary blood vessels into the alveolar walls and spaces. Extensive recent alveolar haemorrhage was seen in eight of these rats; in 16 animals siderophages were present in the alveolar walls and spaces suggesting previous haemorrhage. In 12 of the 17 rats the alveolar spaces contained fibrinous exudate. This exudate showed evidence of organization in seven cases, with the formation of nodules of cellular collagenous tissue. These nodules were becoming incorporated into the wall to produce a focal interstitial pulmonary fibrosis (Fig. 13). A proliferation of alveolar cells occurred in all 17 of the rats with hypertensive pulmonary vascular disease. These cells were either attached to the alveolar walls or lay apparently free in the alveolar spaces. In 16 rats some of these cells contained a brown intracytoplasmic pigment which stained by Perls's method for ferric iron, indicating that these cells were macrophages. The majority of alveolar cells, however, did not contain stainable iron. These cells were large (up to $25 \mu$ diameter) and possessed cytoplasm that was either eosinophilic and granular, or contained numerous small vacuoles, producing a foamy appearance. Their nuclei were large and vesicular, sometimes containing one or two prominent



FIG. 12. Test rat. Thrombotic occlusion of alveolar capillary. Martius-Scarlet-Blue $\times 600$. 


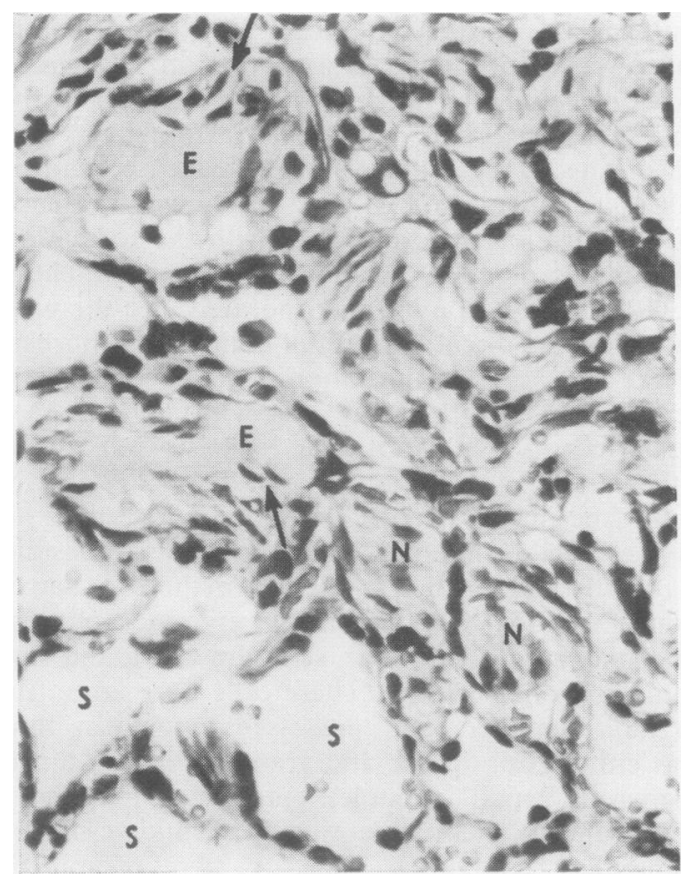

FIG. 13. Test rat. Organization of intra-alveolar exudate leading to interstitial pulmonary fibrosis. Exudate $(E)$ is being invaded by plump fusiform fibroblasts (arrows) to produce nodules $(N)$ of cellular fibrous tissue. The alveolar spaces $(S)$ at the lower left of the picture are unaffected. Haematoxylin and eosin $\times 375$.

nucleoli. Precise identification of alveolar cells was impossible, but their cytological features suggested that they were granular pneumocytes. In three of the rats (nos 1,4 , and 10) with pulmonary vascular disease some of the alveoli were lined by low columnar cells resembling bronchiolar epithelium.

In contrast to the 17 test rats with right ventricular failure, the 11 animals which died of hepatic necrosis showed few exudative lesions in the lung parenchyma. Extensive haemorrhage was observed in one animal, and alveolar siderophages in two animals, but in each instance these lesions accompanied bronchopneumonia or pyaemic abscesses (Tables IV and V). A proliferation of alveolar cells occurred in one rat with hepatic necrosis.

\section{DISCUSSION}

Fulvine and possibly other pyrrolizidine alkaloids are now generally accepted as causing hepatic veno-occlusive disease in Jamaica, and the programme of health education on the island has apparently reduced the incidence of the disease. McFarlane and Branday (1945) described hepatic enlargement and ascites in Jamaican children, which they diagnosed as hepatitis of unknown aetiology, implying that cirrhosis of the liver might be the ultimate result. Royes (1948) concluded that these cases presented a picture of portal cirrhosis very similar to that described in India and Egypt. Hill, Rhodes, Stafford, and Aub (1953) presented their findings in such children and they called the disease serous hepatosis. The occurrence of occlusion of the small hepatic vein radicals in children with this clinical syndrome was first described by Bras, Jelliffe, and Stuart (1954). They proposed the name veno-occlusive disease by which the condition is now widely known. The disease progresses clinically through three overlapping stages (Stuart and Bras, 1957). The acute phase commonly affects young children and is manifested by a sudden onset of ascites and hepatomegaly. In this acute phase there is blockage of the small hepatic veins due to swelling of the intimal tissues. Initially the swelling is oedematous and it may contain a varying amount of blood, but later it becomes organized. There is an intense centrilobular congestion surrounding the blocked veins with loss of liver cells. These acute features have recently been described by Brooks et al. (1970) in electron microscopic studies. The dominant clinical feature of the subacute stage is persistent, often symptomless, hepatomegaly. The underlying pathology is persistent fibrosis in non-portal areas, and blocked centrilobular veins are a regular feature. The clinical picture of the chronic phase is that of cirrhosis of the liver and its complications. The pathology of this phase is a non-portal cirrhosis ; in cases of long standing the origin of the cirrhosis becomes irretraceable.

Bras and his co-workers (Bras et al., 1957; Bras and McLean, 1963) produced centrilobular necrosis and obliterative lesions of the hepatic veins in calves, cows, sheep, and rats by oral administration of watery extracts of Crotalaria fulva. They suggested that ingestion of pyrrolizidine alkaloids in bush tea might be an important aetiological factor in human veno-occlusive disease. In 1956 Stuart and Bras described three children who were admitted to hospital in Barbados complaining of acute abdominal swelling. They gave similar histories of having suffered from whooping cough a few weeks previously, and of having been treated with doses of a bush 
tea prepared from Crotalaria retusa. Examination revealed ascites and tender hepatic enlargement. Liver biopsy specimens showed subendothelial swelling of small hepatic veins with narrowing of their lumens and centrilobular sinusoidal congestion with collapse fibrosis ; in one case the changes amounted to non-portal cirrhosis.

This experimental and clinical evidence leaves little doubt that fulvine and other pyrrolizidine alkaloids contained in Crotalaria and Senecio species can cause hepatic disease in man and other animals by producing centrilobular necrosis and obliterative lesions of the hepatic veins. There appears to be some species variation regarding the predominance of either the parenchymal or vascular lesions in the liver. In man and monkeys hepatic necrosis and venous occlusion occur almost simultaneously (Brooks et al., 1970 ; Allen, Carstens, and Olson, 1967; Allen, Carstens, and Katagiri, 1969), while in rodents (McLean et al., 1964 ; Selzer, Parker, and Sapeika, 1951), chickens (Allen, Childs, and Cravens, 1960; Simpson, Waldroup, and Harms, 1963), and swine (Emmel, Sanders, and Henley, 1935) hepatic necrosis is primary and the venous lesions are only occasionally observed.

The present experiment clearly shows that fulvine will not only produce centrilobular necrosis and veno-occlusive lesions in rats but can also cause hypertensive pulmonary vascular disease in them. This is manifested by right ventricular hypertrophy together with thickening of the pulmonary trunk, medial thickening of the muscular pulmonary arteries, and muscularization of the pulmonary arterioles. Although we did not measure the pulmonary arterial pressure in this experiment, the pulmonary vascular lesions are identical with those which occur in rats given the closely related alkaloid, monocrotaline (Kay and Heath, 1966; Heath and Kay, 1967), and in which we have demonstrated a severe degree of pulmonary arterial hypertension by cardiac catheterization (Kay et al., 1967b). The acute pulmonary arteritis which occurs in rats treated with monocrotaline and fulvine is probably due to a sudden, severe increase in the pulmonary arterial pressure causing necrosis of the vessel wall (Kay and Heath, 1966).

At the dosage of fulvine used in this experiment, rats either died of massive hepatic necrosis within 23 days or survived longer to develop hypertensive pulmonary vascular disease and eventually succumb to right ventricular failure. The higher intragastric dose of fulvine produced 10 early deaths from hepatic necrosis and four late deaths due to right ventricular failure. The lower intraperitoneal dose of fulvine resulted in only one early death from hepatic necrosis, while 13 rats died later from right ventricular failure. We think that if the animals survive the early phase of liver necrosis they will all eventually develop hypertensive pulmonary vascular disease: perhaps the two test rats which died of pneumonia on the 22nd and 23rd days of the experiment would have developed hypertensive pulmonary vascular disease had they survived longer. These animals showed no hepatic necrosis, but there was quantitative evidence of early thickening of the muscular pulmonary arteries (Fig. 7) and pulmonary trunk (Fig. 5). The occurrence of infective lesions in the lungs of seven test rats is not surprising. In most open rat colonies the animals harbour pathogenic organisms affecting the lungs. In young stock rats and in untreated control animals the infection remains latent, but when toxic substances are given to such animals it is not uncommon for pneumonia to develop in a number of them. These lesions probably reflect a general lowering of their natural resistance to infection (Barnes et al., 1964).

The lungs of the 17 rats which developed hypertensive pulmonary vascular disease and died of right ventricular failure after receiving fulvine showed old and recent haemorrhage, alveolar fibrinous exudate, interstitial fibrosis, and a proliferation of alveolar cells. These parenchymal lesions are identical with those which occur in the lungs of rats treated with monocrotaline. They have been termed exudative lesions (Kay, Gillund, and Heath, 1967a) since they could all be the direct or indirect result of chronic exudation of blood or plasma from the small pulmonary blood vessels into the alveolar walls and spaces. Such exudation could result from an alteration in the capillary permeability or to an increase in the capillary intraluminal blood pressure. In all the 17 rats with hypertensive pulmonary vascular disease, many of the alveolar capillaries were occluded by thrombi. The presence of these occlusive lesions would probably increase the capillary intraluminal blood pressure and thus lead to the development of the exudative and proliferative lesions in the lung parenchyma.

There are in the literature two other descriptions of pulmonary lesions in animals treated with fulvine. Gardiner et al. (1965) describe interstitial fibrosis and a proliferation of alveolar cells in rabbits given subcutaneous injections of fulvine but do not mention the heart or pulmonary blood vessels. Barnes et al. (1964) gave a single oral 
dose of fulvine to rats ( $50 \mathrm{mg}$ per $\mathrm{kg}$ body weight) and found that in animals which died within a few days there was an acute necrosis of the liver but the lungs were virtually normal. In contrast, the rats which died from 22 to 68 days after receiving fulvine showed severe lung lesions while the livers were normal apart from the nutmeg pattern of chronic centrilobular venous congestion in some of them. They describe thickened alveolar walls, alveolar oedema and haemorrhage, and a proliferation of large alveolar cells. They also describe and illustrate acute pulmonary arteritis. They state that while there was an impression of an increase in the size of the heart, it was difficult to say whether there was any significant right ventricular hypertrophy. Barnes and his colleagues did not carry out a complete examination of the heart and lungs in their experiments and so did not appreciate the functional significance of the lesions which they observed. They were unable to explain the occurrence of pleural effusions in rats dying with normal livers and damaged lungs several weeks after a single injection of fulvine. Such effusions were no doubt a manifestation of right ventricular failure produced by the hypertensive pulmonary vascular disease which, although present, they had not recognized.

The mechanism by which fulvine and monocrotaline produce pulmonary hypertension is not clear. The possible roles played by changes in alveolar capillaries, alveolar hypoxia, pulmonary mast cell hyperplasia, and 5-hydroxytryptamine have been discussed elsewhere (Kay, Smith, and Heath, 1969). One of the most intriguing problems is that latent period of several weeks which elapses between the administration of the alkaloid and the development of the pulmonary vascular lesions. There is evidence that the pyrrolizidine alkaloids themselves are not toxic substances, but that they are dehydrogenated in the liver to produce highly reactive pyrroll derivatives, which may then be transported to the lungs. It has been shown that the metabolism and excretion of a single toxic dose of a pyrrolizidine alkaloid takes place rapidly and is virtually complete within 24 hours (Mattocks, 1968). Thus the delayed onset of the pulmonary vascular disease cannot result from a prolonged exposure to a toxic metabolite circulating in the blood for several weeks but must follow a short exposure during the metabolism of the alkaloid (Butler, Mattocks, and Barnes, 1970).

Fulvine is now the third substance which has been shown to produce hypertensive pulmonary vascular disease when ingested by rats. We have previously shown that when rats are fed on a diet adulterated with Crotalaria spectabilis seeds which contain monocrotaline, they develop pulmonary arterial hypertension with right ventricular hypertrophy and vascular lesions in the lungs (Kay et al., 1967b). Dr. J. Burns, working in our laboratory at Liverpool, has recently shown that the oral administration of Senecio jacobaea (ragwort) to rats produces right ventribular hypertrophy and hypertensive pulmonary vascular disease. Senecio jacobaea contains six pyrrolizidine alkaloids (Bull, Culvenor, and Dick, 1968), and preparations of it are freely available from herbalists and so-called 'health stores' in Britain where they are recommended for the treatment of various ailments. Although in this paper we have shown that cor pulmonale can occur in association with hepatic veno-occlusive disease in rats, pulmonary vascular disease has never been reported in human cases of veno-occlusive disease of the liver in Jamaica. Our studies convince us that in all patients presenting with unexplained pulmonary hypertension, a careful enquiry should be made into the possibility that the disease might be related to the ingestion of a drug or plant extract. In a separate paper in this journal (Kay, Smith, and Heath, 1971), we review the evidence linking aminorex, a widely used anorexigen, with an epidemic of primary pulmonary hypertension which occurred recently in western Europe.

\section{REFERENCES}

Allen, J. R., Carstens, L. A., and Katagiri, G. J. (1969). Hepatic veins of monkeys with veno-occlusive disease. Arch. Path., 87, 279.

and Olson, B. E. (1967). Veno-occlusive disease in Macaca speciosa monkeys. Amer. J. Path., 50, 653.

— Childs, G. R., and Cravens, W. W. (1960). Crotalaria spectabilis toxicity in chickens. Proc. Soc. exp. Biol. (N.Y.), 104, 434.

Barnes, J. M., Magee, P. N., and Schoental, R. (1964). Lesions in the lungs and livers of rats poisoned with the pyrrolizidine alkaloid fulvine and its $\mathrm{N}$-oxide. J. Path. Bact., 88, 521.

Bras, G., Berry, D. M., and György, P. (1957). Plants as aetiological factor in veno-occlusive disease of the liver. Lancet, 1, 960.

- Brooks, S. E. H., and Watler, D. C. (1961). Cirrhosis of the liver in Jamaica. J. Path. Bact., 82, 503.

— Jelliffe, D. B., and Stuart, K. L. (1954). Veno-occlusive disease of liver with nonportal type of cirrhosis, occurring in Jamaica. Arch. Path., 57, 285.

- and McLean, E. (1963). Toxic factors in veno-occlusive disease. Ann. N.Y. Acad. Sci., III, 392.

Brooks, S. E. H., Miller, C. G., McKenzie, K., Audretsch, J. J., and Bras, G. (1970). Acute veno-occlusive disease of the liver. Fine structure in Jamaican children. Arch. Path., 89, 507.

Bull, L. B., Culvenor, C. C. J., and Dick, A. T. (1968), The Pyrrolizidine Alkaloids, p. 241. North Holland Publishing Company, Amsterdam. 
Butler, W. H., Mattocks, A. R., and Barnes, J. M. (1970). Lesions in the liver and lungs of rats given pyrrole derivatives of pyrrolizidine alkaloids. J. Path., 100, 169.

Emmel, M. W., Sanders, D. A., and Henley, W. W. (1935). Crotalaria spectabilis Roth seed poisoning in swine. J. Amer. vet. med. Ass., 86, 43.

Fulton, R. M., Hutchinson, E. C., and Morgan Jones, A. (1952). Ventricular weight in cardiac hypertrophy. Brit. Heart J., 14, 413.

Gardiner, M. R., Royce, R., and Bokor, A. (1965). Studies on Crotalaria crispata, a newly recognized cause of Kimberley horse disease. J. Path. Bact., 89, 43.

Gomori, G. (1950). A rapid one-step trichrome stain. Amer. J. clin. Path., 20, 661.

Heath, D., and Kay, J. M. (1967). Medial thickness of pulmonary trunk in rats with cor pulmonale induced by ingestion of Crotalaria spectabilis seeds. Cardiovasc. Res., 1, 74.

- Wood, E. H., DuShane, J. W., and Edwards, J. E. (1959). The structure of the pulmonary trunk at different ages and in cases of pulmonary hypertension and pulmonary stenosis. J. Path. Bact., 77, 443.

Hill, K. R., Rhodes, K., Stafford, J. L., and Aub, R. (1953). Serous hepatosis: a pathogenesis of hepatic fibrosis in Jamaican children. Brit. med. J., 1, 117.

Kay, J. M., Gillund, T. D., and Heath, D. (1967a). Mast cells in the lungs of rats fed on Crotalaria spectabilis seeds. Amer. J. Path., 51, 1031.

- Harris, P., and Heath, D. (1967b). Pulmonary hypertension produced in rats by ingestion of Crotalaria spectabilis seeds. Thorax, 22, 176.

_ and Heath, D. (1966). Observations on the pulmonary arteries and heart weight of rats fed on Crotalaria spectabilis seeds. J. Path. Bact., 92, 385.
(1969). Crotalaria Spectabilis, the Pulmonary Hypertension Plant, p. 38. Thomas, Springfield, Illinois. Smith, P., and Heath, D. (1969). Electron microscopy of Crotalaria pulmonary hypertension. Thorax, 24, 511 . (1971). Aminorex and the pulmonary circulation. Thorax 26, 262.

Lendrum, A. C., Fraser, D. S., Slidders, W., and Henderson, R. (1962). Studies on the character and staining of fibrin. J. clin. Path., 15, 401.

Mattocks, A. R. (1968). Toxicity of pyrrolizidine alkaloids. Nature (Lond.), 217, 723.

McFarlane, A. L., and Branday, W. J. (1945). Hepatic enlargement with ascites in children. Brit. med. J., $1,838$.

McLean, E., Bras, G., and György, P. (1964). Veno-occlusive lesions in livers of rats fed Crotalaria fulva. Brit. $J$. exp. Path., 45, 242.

Royes, K. (1948). Infantile hepatic cirrhosis in Jamaica. Carib. med. J., 10, 16.

Schoental, R. (1963). Alkaloid constituents of Crotalaria fulva Roxb., fulvine and its $\mathrm{N}$-oxide. Aust. J. Chem., 16, 233.

Selzer, G., Parker, R. G. F., and Sapeika, N. (1951). An experimental study of Senecio poisoning in rats. Brit. J. exp. Path., 32, 14.

Simpson, C. F., Waldroup, P. W., and Harms, R. H. (1963). Pathologic changes associated with feeding various levels of Crotalaria spectabilis seed to poultry. J. Amer. vet. med. Ass., 142, 264.

Stuart, K. L., and Bras, G. (1956). Veno-occlusive disease of the liver in Barbados. W. Indian med. J., 5, 33 .

(1957). Veno-occlusive disease of the liver. Quart. J. Med. (N.S.). 26, 291. 